\title{
Pengaruh Model Guided Inquiry terhadap Hasil Belajar Siswa pada Pembelajaran Matematika Siswa SD Kota Bengkulu
}

\section{HafizaFahmia}

Universitas Bengkulu

fahmiahafiza06@gmail.com

\author{
V. Karjiyati \\ Universitas Bengkulu \\ vkarjiyati@gmail.com

\section{Dalifa} \\ Universitas Bengkulu \\ dalifa.abdullah@gmail.com
}

\begin{abstract}
This study aims to determine the effect of guided inquiry model on student learning outcomes in Mathematics learning in grade V SD Gugus XII Kota Bengkulu. This type of research is a quasi-experimental research with the design of the study of the matching only pretest-posttest control group design. The population in this study is all students of class V SD group XII consisting of 5 elementary schools. Based on the homogeneity test results, the sample in this study were the students of grade V SDN 99 as the experimental class and the students of class V SDN 81 as the control class. The research instrument used is a matter of objective test consisting of 20 items. Data analysis used is descriptive analysis, prerequisite test and inferential analysis that is $t$-test. Based on data analysis of research results, obtained the average value of posttest result of experimental class using guided inquiry model that is 78,120 and control class using conventional learning that is 62,789. T-test of both sample classes with significance level $\alpha=0.05$, obtained count $=4,730$ whereas ttable $=2,000$, tcount $>$ ttable so that $\mathrm{HO}$ is rejected and $\mathrm{Ha}$ accepted. The increase of study result percentage in experiment class is higher than control class that is $83.36 \%$ in experimental class and control class $33.98 \%$. Thus it can be concluded there is a significant effect of student learning outcomes that follow the learning using guided inquiry model.
\end{abstract}

Keywords: guided inquiry, learning result, math

\begin{abstract}
Abstrak
Penelitian ini bertujuan untuk mengetahui pengaruh model inkuiri terbimbing terhadap hasil belajar siswa pada pembelajaran Matematika di kelas V SD Gugus XII Kota Bengkulu. Jenis penelitian ini adalah penelitian eksperimental semu dengan desain studi yang hanya cocok dengan desain kelompok kontrol pretest-posttest. Populasi dalam
\end{abstract}


penelitian ini adalah semua siswa kelas V SD kelompok XII yang terdiri dari 5 sekolah dasar. Berdasarkan hasil uji homogenitas, sampel dalam penelitian ini adalah siswa kelas V SDN 99 sebagai kelas eksperimen dan siswa kelas V SDN 81 sebagai kelas kontrol. Instrumen penelitian yang digunakan adalah soal tes objektif yang terdiri dari 20 item. Analisis data yang digunakan adalah analisis deskriptif, uji prasyarat dan analisis inferensial yaitu uji-t. Berdasarkan analisis data hasil penelitian, diperoleh nilai rata-rata hasil posttest kelas eksperimen menggunakan model inkuiri terbimbing yaitu 78.120 dan kelas kontrol menggunakan pembelajaran konvensional yaitu 62.789. T-test kedua kelas sampel dengan tingkat signifikansi

$\alpha=0,05$, diperoleh hitung $=4,730$ sedangkan ttabel $=2.000, t$ hitung $>$ ttabel sehingga $\mathrm{HO}$ ditolak dan Ha diterima. Peningkatan persentase hasil belajar di kelas eksperimen lebih tinggi dari kelas kontrol yaitu 83,36\% di kelas eksperimen dan kelas kontrol 33,98\%. Dengan demikian dapat disimpulkan ada pengaruh yang signifikan hasil belajar siswa yang mengikuti pembelajaran menggunakan model inkuiri terbimbing.

Kata kunci: inkuiri terbimbing, hasil belajar, matematika

\section{Pendahuluan}

Salah satu bidang ilmu yang sangat bermanfaat dalam kehidupan yaitu Matematika. Hal tersebut dikarenakan setiap permasalahan dalam kehidupan sehari-hari selalu diselesaikan dengan Matematika. Contohnya kegiatan jual beli, menghitung luas daerah, dan lain-lain. Hal ini membuat siswa mampu untuk menganalisis, berpikir secara kreatif, berpikir logis, sistematis, dan kritis,serta memiliki kemampuan bekerja sama.

Kenyataan di lapangan prestasi belajar Matematika di Indonesia menunjukkan hasil yang kurang memuaskan. Berdasarkan hasil Trends in International Mathematics and Science Study (TIMSS), pada tahun 2015 Indonesia berada di peringkat 44 dari 49 negara dengan rata-rata skor prestasi Matematika siswa adalah 397. Untuk wilayah Provinsi Bengkulu, berdasarkan hasil Ujian Sekolah (US) untuk tingkat Sekolah Dasar (SD), nilai rata-rata Matematika sebesar 58,45, Bahasa Indonesia sebesar 63,71 dan IPA sebesar 66,42 (Harian Rakyat Bengkulu, 16 Juni 2017). Ratarata nilai Matematika lebih rendah dibandingkan nilai rata-rata mata pelajaran Bahasa Indonesia dan IPA.

Rendahnya prestasi belajar Matematika siswa dipengaruhi oleh berbagai faktor, menurut Purwanto (2010: 107), salah satu faktor yang mempengaruhi prestasi belajar yaitu strategi yang digunakan guru dalam proses pembelajaran. Tidak tepatnya strategi pembelajaran yang digunakan, mengakibatkan siswa sulit menerima materi yang dipelajari. Selain itu adanya anggapan siswa bahwa Matematika merupakan mata pelajaran yang rumit. Dikatakan rumit karena Matematika merupakan ilmu yang kajian objeknya bersifat abstrak, artinya hanya ada dalam pemikiran.

Abstraknya objek Matematika menjadi kesulitan tersendiri bagi siswa dalam mempelajarinya. Tidak hanya siswa, guru pun mengalami kendala dalam mengajarkan Matematika. Terutama untuk mengkonkretkan materi yang disampaikan.

Berdasarkan teori belajar Matematika Jean Piaget, perkembangan intelektual anak usia SD berada pada tahap operasional konkret. Selain itu berdasarkan teori Bruner kemampuan mental anak berkembang secara bertahap, mulai dari hal yang 
sederhana menuju yang rumit, dan dari yang nyata (konkret) ke yang abstrak. Dengan demikian, selama proses pembelajaran Matematika, guru hendaknya memulai dengan menggunakan benda-benda yang bersifat konkret. Benda yang bersifat konkret akan memudahkan anak untuk memanipulasi dan merasakan langsung wujud dari benda tersebut. Dengan demikian akan sesuai dengan karakteristik anak usia SD. Menurut Desmita (2012: 35), terdapat empat karakteristik anak usia SD yaitu senang bekerja secara berkelompok, senang bermain, senang bergerak, dan senang melakukan sesuatu secara langsung.

Dalam pembelajaran Matematika, agar konsep tertanam dengan baik guru dapat menggunakan model pembelajaran yang sesuai dengan karakteristik anak SD. Melalui model pembelajaran, anak bisa bergerak menemukan konsep dari materi yang dipelajari secara sendiri. Model inkuiri terbimbing (guided inquiry) sangat cocok untuk anak usia SD, karena selama kegiatan pembelajaran usia SD masih memerlukan bimbingan agar kegiatan pembelajaran lebih terarah. Bimbingan yang dimaksud dalam model ini yaitu siswa diberikan bantuan seperti kelengkapan fasilitas yang dibutuhkan serta tindakan guru sebagai penunjuk jalan.

Model guided inquiry adalah pembelajaran dengan pendekatan inquiry. Dalam proses pembelajaran guided inquiry, siswa tidak hanya duduk diam dan mendengarkan penyampaikan materi dari guru, tetapi melakukan penemuan untuk menjawab permasalahan yang ajukan guru, dimana dalam proses penemuan siswa mendapatkan bimbingan secara intensif. Dalam proses pembelajarannya, bimbingan yang guru berikan kepada siswa berupa pertanyaan-pertanyaan dan diskusi mulitiarah yang mengiring siswa agar bisa memahami konsep yang dipelajari.

Keuntungan dari pembelajaran guided inquiry salah satunya, yaitu siswa memiliki peluang besar untuk melakukan penemuan, sehingga siswa akan segera mendapatkan hasil dari materi yang mereka pelajari. Hal ini didukung oleh pendapat Bruner (Anam, 2015: 16), bahwa dengan pembelajaran guided inquiry, pemahaman siswa akan konsep dasar dan ide-ide menjadi lebih baik. Selain itu, Sanjaya (2012: 208-209) mengemukakan bahwa salah satu kelebihan model guided inquiry yaitu menjadikan pembelajaran lebih bermakna, karena ketiga aspek mencakup kognitif, afektif, dan psikomotor mengalami perkembangan secara seimbang. Hal tersebut akan berpengaruh terhadap hasil belajar siswa. Menurut Susanto (2014: 5) hasil belajar yaitu adanya perubahan yang terjadi pada diri siswa, baik pada aspek kognitif, afektif, maupun psikomotor.

Berdasarkan analisis kurikulum 2013, pada mata pelajaran Matematika di kelas V terdapat materi volume bangun ruang, dengan Kompetensi Dasar (KD) 3.7 menjelaskan, dan menentukan volume bangun ruang dengan menggunakan satuan volume (seperti kubus satuan). Bangun ruang yang dipelajari yaitu kubus dan balok. Materi ini dalam aplikasinya, diajarkan dengan menggunakan model guided inquiry. Dalam proses pembelajarannya, siswa akan dibagi menjadi beberapa kelompok belajar, dimana masing-masing kelompok diberikan Lembar Kegiatan Siswa (LKS) dan alat peraga model kubus, model balok dan kubus satuan. Dalam kelompok, siswa akan dibimbing menemukan konsep volume kubus dan balok. Bimbingan diberikan hingga siswa menemukan rumus volume kubus dan balok.

Berdasarkan hasil penelitian yang dilakukan oleh Putra, dkk (2014), bahwa pembelajaran dengan model inkuiri terbimbing berbantuan media grafis berpengaruh positif terhadap hasil belajar Matematika siswa kelas IV SD di Gugus 4 Kecamatan Busungbiu Kabupaten Buleleng. Selain itu berdasarkan hasil penelitian yang dilakukan Krisnayanti, dkk (2017), model pembelajaran inkuiri terbimbing berbantuan tutor sebaya berpengaruh terhadap kompetensi pengetahuan Matematika siswa kelas V SD Gugus Kompyang Sujana Kecamatan Denpasar Barat 
Tahun Pelajaran 2016/2017. Hal ini dapat diartikan bahwa model guided inquiry memiliki pengaruh yang positif terhadap hasil belajar dan kompetensi pengetahuan Matematika siswa SD.

\section{Metode}

Jenis penelitian ini menggunakan jenis penelitian kuantitatif, dengan metode eksperimen semu. Dalam metode eksperimen terdapat dua kelompok, yaitu kelompok eksperimen dan kelompok kontrol.

Penelitian ini dilakukan untuk mengetahui pengaruh model pembelajaran yang digunakan terhadap hasil belajar matematika siswa, dimana akan diujikan pada kelas yang berbeda. Kelas pertama menjadi kelas eksperimen, kegiatan pembelajaran menggunakan model guided inquiry. Sedangkan kelas kedua menjadi kelas kontrol, dalam proses pembelajarannya menggunakan pembelajaran konvensional. Desain penelitian yang digunakan yaitu The Matching only PretestPosttest Control Group Design. Untuk memperoleh kelompok yang benar-benar ekuivalen (setara), kelas eksperimen dan kontrol disetarakan melalui pretest untuk melihat kemampuan awal siswa. Setelah diperoleh hasil yang homogen, selanjutnya dilakukan proses pembelajaran pada kedua kelas denganmateri yang sama yaitu volume bangun ruang (kubus dan balok).

Dalam penelitian ini, yang menjadipopulasiyaitu seluruh siswa kelas V SD gugus XII Kota Bengkulu yang terdiri dari 5 SD, yaitu SDN 20, SDN 81, SDN 35, SDN 99, dan SDN 60.

Teknik pengambilan sampel yang digunakan yaitu teknik cluster sampling. Menurut Winarni (2011: 190), teknik cluster sampling yaitu mengambil beberapa kelas anggota populasi diantara kelas-kelas yang homogen. Untuk mendapatkan kelas sampel yang homogen, kelas yang menjadi sampel pada penelitian ini dipilih dengan cara melakukan uji homogenitas. Uji homogenitas yang peneliti lakukan menggunakan data dokumentasi nilai ulangan matematika siswa yang diperoleh dari wali kelas. Setelah peneliti melakukan uji homogenitas, diperoleh data bahwa kelas V SDN 81, kelas V SDN 99, dan kelas V SDN 20 adalah kelas yang homogen sehingga dapat dijadikan sampel penelitian. Selanjutnya peneliti memilih dua kelas sebagai kelas sampel dan satu kelas dijadikan kelas uji coba instrumen. Diperoleh kelas V SDN 99 menjadi kelas eksperimen, kelas V SDN 81 menjadi kelas kontrol, dan kelas V SDN 20 menjadi kelas uji coba instrumen.

Instrumen yang digunakan dalam penelitian ini yaitu lembar tes, dimana tes yang digunakan berbentuk soal tes objektif terdiri dari 20 butir soal dengan 4 pilihan. Sebelum uji coba instrumen, terlebih dahulu dilakukan validasi ahli oleh ibu Atmawati Malik, S.Pd selaku wali kelas V SDN 20 kota Bengkulu. Berdasarkan hasil validasi, diperoleh semua butir soal telah memenuhi persyaratan untuk digunakan sebagai instrumen penelitian dengan kategori baik.

Berdasarkan hasil uji coba instrumen, diperoleh semua butir soal valid, reliabel dengan $r_{11}=0,82$, taraf kesukaran yang bervariasi dan memiliki daya pembeda cukup dan baik. Dengan demikian dapat disimpulkan semua butir soal layak digunakan sebagai soal pretest dan posttest pada kelas eksperimen dan kelas kontrol.

Teknik pengumpulan data yang digunakan pada penelitian ini yaitu dokumentasi berupa nilai hasil ulangan Matematika siswa semester I tahun ajaran 2017/2018 dan tes (pretest dan posttest. Dokumentasi nilai hasil ulangan siswa digunakan untuk menghitung uji homogenitas sampel. Data dokumentasi ini diperoleh dari wali kelas. 
Pretest dilaksanakan satu hari sebelum perlakuan diberikan. Masing-masing siswa diberikan lembar soal pretest. Setelah pretest dilaksanakan, kedua kelas diberikan perlakuan, dimana pada kelas eksperimen menggunakan model pembelajaran guided inquiry sedangkan pada kelas kontrol menggunakan pembelajaran konvensional. Setelah kegiatan pembelajaran usai, siswa diberikan soal posttest untuk mengetahui kemampuan yang diperoleh siswa setelah mengikuti proses pembelajaran.

Analisis data yang dilakukan meliputi analisis deskriptif yaitu penyajian data melalui tabel, perhitungan skor rata-rata (mean), dan varian; analisis uji prasyarat yaitu dengan melakukan uji normallitas dan uji homogenitas, dan analisis inferensial yaitu dengan uji-independen.

\section{Hasil}

Data hasil pretest menunjukkan pada kelas eksperimen nilai tertinggi yaitu 75 , nilai terendah yaitu 15 dengan jumlah nilai 1225 dan rata-rata 42,603. Standar deviasi 16,058 , dengan varian 257,883 . Pada kelas kontrol nilai tertinggi yaitu 75 , nilai terendah yaitu 10 dengan jumlah nilai 1360 dan rata-rata 46,862. Standar deviasi 19,796 , dengan varian 391,908 .

Data hasil posttest menunjukkan pada kelas eksperimen nilai tertinggi yaitu 100, nilai terendah yaitu 45 dengan jumlah nilai 2265 dan rata-rata 78,120 . Pada kelas kontrol nilai tertinggi yaitu 80, nilai terendah yaitu 35 dengan jumlah nilai 1820 dan rata-rata 62,789. Berdasarkan rata-rata pretest pada kelas eksperimen dan kelas kontrol, tidak terdapat perbedaan yang signifikan, artinya kemampuan awal yang dimiliki siswa pada kelas eksperimen dan kelas kontrol adalah sama. Sedangkan pada hasil posttest, terdapat perbedaan yang signifikan rata-rata pada kelas eksperimen dan kelas kontrol.

Sebelum melakukan pengujian hipotesis menggunakan uji-t, peneliti melakukan uji prasyarat hipotesis yaitu uji normalitas dan uji homogenitas. Hal ini bertujuan agar data yang ingin diuji berdistribusi normal dengan varian yang homogen. Uji normalitas dan uji homogenitas yang peneliti lakukan yaitu data hasil pretest dan posttest siswa.

Berdasarkan uji normalitas hasil pretest dan posttest siswa, diperoleh hasil pretest maupun posttest pada kelas eksperimen dan kelas kontrol berdistribusi normal. Pada hasil pretest kelas eksperimen diperoleh $\mathrm{X}_{2}$ hitung $=7,5863$ dan pada kelas kontrol $\mathrm{X}_{2}$ hitung $=7,4628$, dengan $\mathrm{X}_{2}$ tabel $=11,070$. Pada hasil posttest kelas eksperimen diperoleh $\mathrm{X}_{2}$ hitung $=7,1565$ dan pada kelas kontrol $\mathrm{X}_{2}$ hitung $=6,4840$, dengan $\mathrm{X}$ 2tabel $=11,070$.

Berdasarkan uji homogenitas hasil pretest siswa, diperoleh $\mathrm{F}_{\text {hitung }}=1,519$ dengan $\mathrm{F}_{\text {tabel }}$ = 1,96. Dari hasil perhitungan menunjukkan $\mathrm{F}_{\text {hitung }}<\mathrm{F}_{\text {tabel, }}$ maka dapat disimpulkan bahwa hasil pretest siswa pada kelas eksperimen dan kelas kontrol adalah homogen.Berdasarkan uji homogenitas hasil posttest siswa, Diperoleh $\mathrm{F}_{\text {hitung }}=1,587$ dengan $\mathrm{F}_{\text {tabel }}=1,96$. Dari hasil perhitungan menunjukkan $\mathrm{F}_{\text {hitung }}<\mathrm{F}_{\text {tabel, }}$ maka dapat disimpulkan bahwa hasil posttest siswa pada kelas eksperimen dan kelas kontrol adalah homogen.Setelah uji prasyarat hipotesis selesai dilakukan dengan hasil data yang normal dan homogen, maka peneliti melakukan uji hipotesis yaitu dengan uji-t.

Berdasarkan hasil uji hipotesis (Uji-t) pretest siswa pada kelas eksperimen dan kelas kontrol diperoleh thitung $=0,121$, dengan tabel $=2,000$. Karena thitung $<t_{\text {tabel, }}$ maka tidak terdapat perbedaan hasil pretest antara kelas eksperimen dan kelas kontrol. Berdasarkan hasil uji hipotesis (Uji-t) posttest siswa pada kelas eksperimen dan 
kelas kontrol diperoleh thitung $=4,730$, dengan tabel $=2,000$. Karena thitung $>t_{\text {tabel, }}$ sehingga terdapat perbedaan hasil posttest antara kelas eksperimen dan kelas kontrol. Adapun rekapitulasi hasil penelitian dapat dilihat pada tabel 1.

Tabel 1. Rekapitulasi Hasil Penelitian

\begin{tabular}{|c|c|c|c|c|}
\hline \multirow{2}{*}{ Deskripsi } & \multirow{2}{*}{$\begin{array}{c}\text { Pretest } \\
\text { Eksperimen }\end{array}$} & \multicolumn{3}{|c|}{ Posttest } \\
\hline & & Kontrol & Eksperimen & Kontrol \\
\hline Nilai Tertinggi & 75 & 75 & 100 & 80 \\
\hline Nilai Terendah & 15 & 10 & 45 & 35 \\
\hline Jumlah & 1225 & 1360 & 2265 & 1820 \\
\hline Rata-rata & 42,603 & 46,862 & 78,120 & 62,789 \\
\hline Standar Deviasi & 16,058 & 19,796 & 10,930 & 13,770 \\
\hline Varian & 257,883 & 391,908 & 119,467 & 189,629 \\
\hline \multicolumn{5}{|l|}{ Uji Normalitas } \\
\hline X2 hitung & 7,5863 & 7,4628 & 7,1565 & 6,4840 \\
\hline $\mathrm{X} 2$ tabel & 11,070 & 11,070 & 11,070 & 11,070 \\
\hline
\end{tabular}

Tabel 2. Uji Homogenitas

\begin{tabular}{lll}
\hline F hitung & 1,519 & 1,587 \\
F tabel & 1,96 & 1,96 \\
Uji Hipotesis & & \\
t hitung & 0,121 & 4,730 \\
t tabel & 2,000 & 2,000 \\
\hline
\end{tabular}

\section{Pembahasan}

Tahap awal penelitian, yaitu dilaksanakan pretest pada kelas eksperimen dan kelas kontrol. Pretest dilaksanakan satu hari sebelum perlakuan diberikan. Berdasarkan hasil pretest tidak terdapat perbedaan yang signifikan kemampuan awal siswa pada kelas eksperimen dan kelas kontrol.

Setelah pretest dilaksanakan, kedua kelas diberikan perlakuan, dimana pada kelas eksperimen menggunakan model pembelajaran guided inquiry sedangkan pada kelas kontrol menggunakan pembelajaran konvensional.

Pada kelas eksperimen, proses pembelajaran dimulai dari kegiatan awal yaitu apersepsi, dilanjutkan kegiatan inti, dimana siswa belajar berkelompok. Siswa diajukan permasalahan mengenai volume kubus dan balok. Dalam kelompok, siswa dibimbing menyelesaikan masalah melalui kegiatan penemuan. Siswa dibimbing menemukan rumus volume kubus dan balok dengan langkah-langkah kegiatan yang terdapat pada LKS. Proses penemuan menggunakan alat peraga model kubus, model balok, dan kubus satuan. Siswa dibimbing memanipulasi alat peraga dengan cara memasukkan satu persatu kubus satuan ke dalam model kubus dan model balok. Selanjutnya siswa dibimbing menghitung banyaknya jumlah kubus satuan pada tiap rusuk, dan jumlah keseluruhan kubus satuan yang terdapat dalam model kubus dan model balok. Guru memberikan bimbingan hingga siswa benar-benar menemukan rumus volume kubus dan balok, dan mampu menghitung volume bangun ruang tersebut menggunakan rumus. Uraian di atas sesuai dengan pendapat Anam (2015: 17), bahwa dalam menerapkan model guided inquiry siswa tidak hanya duduk diam dan mendengarkan penyampaikan materi dari guru, tetapi melakukan penemuan untuk menjawab permasalahan yang ajukan guru, dimana dalam proses penemuan siswa mendapatkan bimbingan secara intensif.

Siswa sangat antusias mengikuti proses pembelajaran, hal ini dibuktikan dengan perilaku siswa yang selalu ingin bertanya selama kegiatan belajar berlangsung. Ditambah lagi dengan bantuan alat peraga model kubus, model balok dan kubus 
satuan, yang membuat semua siswa ingin mencoba untuk memanipulasi alat peraga tersebut. Hal ini sesuai dengan pendapat Desmita (2012: 35), mengenai karakteristik anak SD, dimana anak usia SD senang bekerja secara berkelompok, senang bermain, senang bergerak, dan senang mengerjakan sesuatu secara langsung.

Kegiatan belajar menemukan rumus volume kubus dan balok, memberikan kesempatan kepada siswa untuk menemukan sendiri pengetahuannya, sehingga menghindarkan siswa dari belajar yang bersifat hafalan. Selain itu, siswa menjadi lebih mudah mengingat rumus volume kubus dan balok. Hal ini sesuai dengan pendapat Putra (2013: 104-107), mengenai kelebihan dari model guided inquiry yaitu: 1) potensi intelektual anakmeningkat, 2) pembelajaran berpusat pada siswa, 3) memperpanjang proses ingatan, 4) memperoleh pengetahuan bersifat penyelidikan, 5) konsep diri siswa dapat terbentuk dan berkembang, 6) siswa terhindar dari belajar dengan hafalan, 7) siswa berkesempatan mengatur informasi yang didapatkan sendiri. Berdasarkan uraian di atas, dapat dilihat bahwa pembelajaran dengan model guided inquiry memacu siswa memiliki gairah yang tinggi untuk mengikuti kegiatan pembelajaran.

Pada kelas kontrol, kegiatan pembelajaran dilakukan secara konvensional dimana pembelajaran berpusat pada guru. Langkah-langkah pembelajaran konvensional dimulai dari guru memberikan apersepsi dilanjutkan menerangkan bahan ajar secara verbal hingga tuntas, pemberian contoh soal, dilanjutkan kegiatan tanya jawab, pemberian tugas, mengkonfirmasikan tugas yang siswa kerjakan, dan menyimpulkan materi pelajaran.

Setelah kegiatan pembelajaran usai, siswa diberikan soal posttest untuk mengetahui kemampuan yang diperoleh siswa setelah mengikuti proses pembelajaran. Berdasarkan hasil posttest terdapat perbedaan hasil posttest kelas eksperimen dan kelas kontrol.

Berdasarkan persentase peningkatan hasil belajar pretest dan posttest kedua kelas, pada kelas eksperimen mengalami peningkatan sebesar $83,36 \%$, sedangkan pada kelas kontrol peningkatan sebesar 33,98\%. Hal ini menunjukkan bahwa terdapat pengaruh yang signifikan hasil belajar siswa yang mengikuti pembelajaran menggunakan model guided inquiry.

\section{Simpulan}

Berdasarkan hasil penelitian yang telah dilaksanakan serta temuan dan pembahasan yang telah diuraikan, peneliti dapat menarik kesimpulan sebagai berikut: terdapat pengaruh yang signifikan hasil belajar siswa yang mengikuti pembelajaran menggunakan model guided inquiry. Hal ini sesuai dengan pendapat Sanjaya (2012: 208-209) mengenai kelebihan model guided inquiry, salah satunya yaitu menjadikan pembelajaran lebih bermakna, karena ketiga aspek mencakup kognitif, afektif, dan psikomotor mengalami perkembangan secara seimbang. Dengan demikian berpengaruh terhadap hasil belajar siswa. Selain itu, berdasarkan hasil penelitian yang dilakukan Putra, dkk (2014), bahwa pembelajaran dengan model inkuiri terbimbing berbantuan media grafis berpengaruh positif terhadap hasil belajar Matematika siswa, dan hasil penelitian yang dilakukan Krisnayanti, dkk (2017), bahwa model pembelajaran inkuiri terbimbing berbantuan tutor sebaya berpengaruh terhadap kompetensi pengetahuan Matematika siswa kelas V SD.

\section{Saran}

Berdasarkan hasil penelitian yang telah dilakukan, maka peneliti memberikan saran: 
1. Bagi guru

a. Dalam upaya meningkatkan kualitas belajar Matematika siswa, guru dapat menggunakan model guided inquiry karena siswa khususnya usia SD masih memerlukan bimbingan dalam proses pembelajaran.

b. Agar keefektifan pembelajaran model guided inquiry dapat terpelihara dengan baik, dalam proses pembelajaran guru menjadi penunjuk jalan dan fasilitator yang efektif, dengan memperhatikan beberapa hal penting yaitu: 1) sebelum kegiatan pembelajaran dimulai, sebaiknya guru menyiapkan alat dan bahan yang dibutuhkan dalam proses pembelajaran, seperti alat peraga dan LKS atau LKPD, 2) Dalam memberikan bimbingan selama proses pembelajaran, guru sebaiknya memperhatikan tiap individu dalam kelompok. Hal ini bertujuan agar siswa yang berkemampuan rendah dapat mengikuti proses pembelajaran dengan baik sehingga tidak mengalami ketertinggalan.

2. Bagi peneliti yang ingin menindaklanjuti hasil penelitian

a. Disarankan dalam kegiatan penemuan konsep, menggunakan alatperaga yang lebih menarik dan bervariasi, sesuai dengan materi pelajaran yang akan dipelajari nantinya.

b. Hasil penelitian ini diharapkan dapat dijadikan sebagai bahan kajian penelitian yang relevan, khususnya sebagai penunjang penelitian dengan kajian yang lebih luas dan mendalam mengenai model guided inquiry.

\section{Referensi}

Anam, K. 2015. Pembelajaran Berbasis Inkuiri. Yogyakarta: Pustaka Pelajar.

Desmita. 2012. Psikologi Perkembangan Peserta Didik. Bandung: Remaja Rosdakarya Offset.

Krisnayanti dkk. 2017. Pengaruh Model Pembelajaran Inkuiri Terbimbing Berbantuan Tutor Sebaya Terhadap Kompetensi Pengetahuan Matematika Siswa Kelas. dalam:

https://ejournal.undiksha.ac.id/index.php/JJPGSD/article/viewFile/10729/6 832

Purwanto, N. 2010. Psikologi Pendidikan. Bandung: Rosdakarya.

Putra, S., R. 2013. Desain Belajar Mengajar Kreatif Berbasis Sains. Yogyakarta: Diva Press.

Putra, dkk. 2014. Pengaruh Model Pembelajaran Inkuiri Terbimbing Berbantuan Media Grafis Terhadap Hasil Belajar Matematika Kelas IV SD Gugus 4 Kecamatan Busungbiu. dalam:

https://ejournal.undiksha.ac.id/index.php/JJPGSD/article/view/2037

Rakyat Bengkulu. 2017. Kota tertinggi Kaur Terendah. dalam: http://harianrakyatbengkulu.com/ver3/2017/06/16/kota-tertinggi-kaurterendah/

Sanjaya. 2012. Strategi Pembelajaran Berorientasi Standar Proses Pendidikan. Jakarta: Kencana Prenada Media Group.

Susanto, A. 2014. Teori Belajar dan Pembelajaran di Sekolah Dasar. Jakarta: Fajar Interpratama Mandiri.

Winarni, E., W. 2011. Penelitian Pendidikan. Bengkulu: FKIP UNIB. 